\title{
Article \\ Measurement of Shear Strengths of Cu Films Using Precise Chip Forming
}

\author{
Jeong-Heon Lee ${ }^{1}$ and Jae B. Kwak ${ }^{1,2, *(1)}$ \\ 1 School of Mechanical System and Automotive Engineering, Chosun University, 309 Pilmun-daero, \\ Gwangju 61452, Korea; shilfi21@chosun.kr \\ 2 Department of Mechanical Engineering, Chosun University, 309 Pilmun-daero, Gwangju 61452, Korea \\ * Correspondence: jaekwak@chosun.ac.kr
}

check for

updates

Citation: Lee, J.-H.; Kwak, J.B.

Measurement of Shear Strengths of

$\mathrm{Cu}$ Films Using Precise Chip

Forming. Materials 2022, 15, 948.

https://doi.org/10.3390/ma15030948

Academic Editor: Jordi Sort

Received: 9 December 2021

Accepted: 25 January 2022

Published: 26 January 2022

Publisher's Note: MDPI stays neutral with regard to jurisdictional claims in published maps and institutional affiliations.

Copyright: (c) 2022 by the authors. Licensee MDPI, Basel, Switzerland. This article is an open access article distributed under the terms and conditions of the Creative Commons Attribution (CC BY) license (https:// creativecommons.org/licenses/by/ $4.0 /)$.

\begin{abstract}
The mechanical properties of thin films are under-researched because of the challenges associated with conventional experimental methods. We demonstrate a technique for determining the intrinsic shear strength and strain of thin films using a nano-cutting technique based on an orthogonal cutting model with precise control of the cutting system. In this study, electroplated $\mathrm{Cu}$ films with thicknesses of $1.5 \mu \mathrm{m}$ and $5 \mu \mathrm{m}$ and a sputtered $\mathrm{Cu}$ film with a thickness of $130 \mathrm{~nm}$ were fabricated to evaluate the mechanical strength. Experiments revealed a shear strength of approximately $310 \mathrm{MPa}$ with a shear strain of 1.57 for the electroplated $\mathrm{Cu}$ film and a shear strength of $389 \mathrm{MPa}$ with a shear strain of 2.03 for the sputtered $\mathrm{Cu}$ film. In addition, $\mathrm{X}$-ray diffraction analysis was performed to correlate the experimental results.
\end{abstract}

Keywords: mechanical properties; thin films; shear strength; strain; nano cutting; copper; X-ray diffraction

\section{Introduction}

Thin films are becoming increasingly important for various industrial applications, such as microelectronics and electronic devices. Among the most common reasons for the failure of thin films is surface cracking owing to mechanical loading, such as tension, compression, and impact [1,2]. In particular, Jörg et al. reported that the electrical resistance of Mo thin films as traces is dramatically increased at some amount of elongation under tension loading, attributed to surface crack occurrence [2]. The increasing slimness of electronic devices and flexible printed circuit boards (PCBs) requires thinner $\mathrm{Cu}$ traces for PCBs with narrow pitch sizes, which results in reliability issues owing to surface cracks and delamination [3,4]. Consequently, we face challenges in understanding the deformation and failure mechanisms of thin film structures involved in mechanical loading. According to the nature of the material strength, shear dislocations result in deformation against the load. In this study, the idea of a metal chip forming process, the cutting or machining process, is used to quantitatively determine the shear strengths and strains of $\mathrm{Cu}$ films through extensive plastic deformation.

Generally, mechanical properties are defined as Young's modulus, yield strength, tensile strength, etc., and are obtained from tensile or compression tests for bulk materials as established by ASTM standards. However, these conventional methods are not applicable to thin film materials with sub-micrometer thickness. Therefore, many studies have attempted to determine the intrinsic strengths of thin films, including nano-indentation and nano-bulge testing. The nano-indentation method is widely used to obtain film properties, including Young's modulus and the hardness of thin films through indentation tests with a specified tip [5-11]. However, this method has limitations when applied to very thin films, owing to the substrate effects and the size of the indenter tip. Ritcher et al. [12], Chen et al. [13], Saha and Nix [14], and Pham and Fang [15] investigated not only the elastic inhomogeneity of thin films depending on various substrates but also the considerable 
effect of pile-up and sink-in attributed to the strain hardening of the material in nanoindentation tests. In turn, the nano-bulge method measures stress-strain curves through thin film deflection against the pressure applied to the specimen by blowing a uniform distribution load on the specimen. This method can determine the stress-strain curve of the material, thereby obtaining Young's modulus and tensile strength [16,17]. However, sample preparation and handling issues (i.e., clamping) are problematic. In addition, this method may not be appropriate for ceramic films because of the nature of brittle materials. In this study, a technique for evaluating the shear strength of $\mathrm{Cu}$ films was researched using a cutting system and an analysis of the fracture mechanism of the electroplated $\mathrm{Cu}$ films.

Electroplated and sputtered $\mathrm{Cu}$ films are considered to be nano-crystalline structures, where surface cracks are typical fracture failures. To determine the shear strength as a fracture resistance of the $\mathrm{Cu}$ films, a precise chip-forming process was conducted based on the cutting test suggested by the Merchant's cutting model [18,19]. According to the Merchant's cutting model, chip formation is related to the strength of the material when it is subjected to plastic deformation. Consequently, at the root of the chip, a shear angle of $45^{\circ}$ develops between the shear plane and the cutting plane, designated as $\varnothing$ in Figure 1 . In this study, films were cut in a diagonal direction from the surface of the film in thickness, as it is practically difficult to cut flat thin films in the horizontal direction. Therefore, the diagonal cutting test was conducted by precisely controlling the blade using two synchronized piezo transducer stages, one in the vertical direction and the other in the horizontal direction. As shown in Figure 1, the blade simultaneously cuts the thin film in both the vertical and horizontal directions, resulting in diagonal cutting. Consequently, orthogonal $\mathrm{F}_{\mathrm{t}}$ and $\mathrm{F}_{\mathrm{c}}$ were determined to be resistant forces against diagonal cutting. Figure 1 shows the procedure of the orthogonal cutting, and the chip formation process from cutting with a specific blade geometry, such as the rake angle $(\alpha)$ and width $(\mathrm{w})$. Using the parameters shown in Figure 1, the shear strength $\left(\tau_{s}\right)$ was determined using Equation (1).

$$
\tau_{s}=\frac{F_{s}}{A_{s}}=\frac{\left(F_{c} \cos \varnothing-F_{t} \sin \varnothing\right) \sin \varnothing}{w t},
$$

where $F_{s}$ is the shear force, $A_{s}$ is the area of the shear plane, $F_{c}$ is the cutting force in the horizontal direction, $F_{t}$ is the thrust force in the vertical direction, $\varnothing$ is the angle between the shear plane and the horizontal cutting plane, $w$ is the width of the blade, and $t$ is the thickness of the cut material.

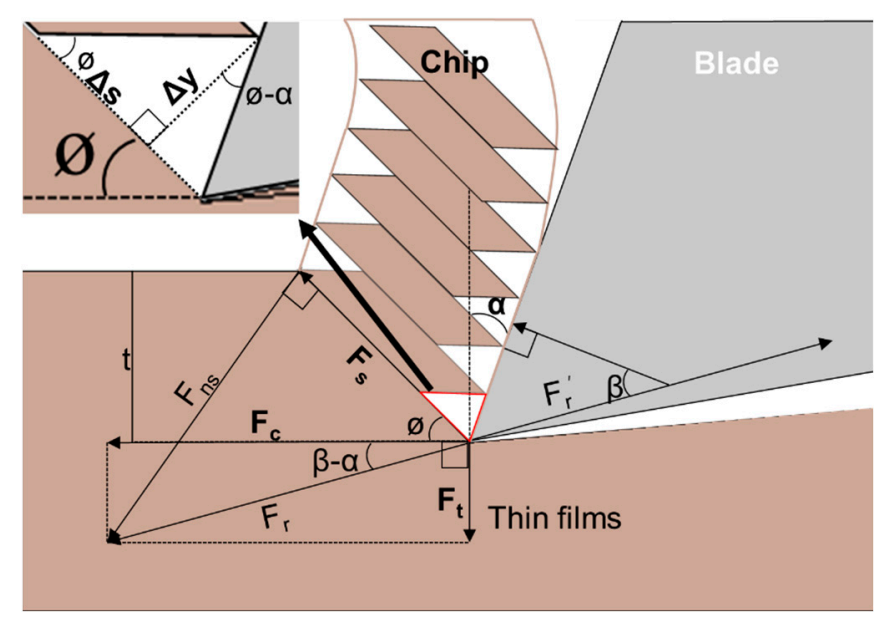

Figure 1. Merchant's orthogonal cutting model. 
According to the Merchant's model, the shear plane angle is associated with both the friction angle and rake angle, which is also related to $F_{t}$ and $F_{c}$ and expressed as Equation (2).

$$
\varnothing=\frac{\pi}{4}-\frac{1}{2}(\beta-\alpha)=\frac{\pi}{4}-\frac{1}{2} \tan ^{-1}\left(\frac{F_{t}}{F_{c}}\right),
$$

where $\beta$ is the friction angle between the formed chip and the blade rake surface, and $\alpha$ is the rake angle of the blade.

During the cutting process, the chip is naturally formed as a continuous structure of a group of parallel shear plates. Therefore, the shear strain of the material can be determined from the shear deformation and the thickness of the shear plate, as expressed by Equation (3).

$$
\gamma=\frac{\Delta s}{\Delta y}=\frac{\cos \alpha}{\sin \varnothing \cos (\varnothing-\alpha)}
$$

where $\Delta s$ is the shear deformation in the shear direction, and $\Delta y$ is the thickness of the primary shear zone, as shown in the upper left corner of Figure 1.

\section{Experimental}

\subsection{Sample Preparation}

In this study, several $\mathrm{Cu}$ thin films with different thicknesses were prepared using two fabrication methods: an electroplating process [20] and a magnetron sputtering process [21]. In addition, two types of Si wafer substrates were prepared. One substrate was sputtered by $\mathrm{Cu}$ with a thickness of approximately $5 \mathrm{~nm}$ for electrical conductivity before the $\mathrm{Cu}$ electroplating process, and another substrate was well cleaned with alcohol before magnetron sputtering. For the electroplated $\mathrm{Cu}$ film process, $\mathrm{CuSO} 4 \cdot 5 \mathrm{H}_{2} \mathrm{O}(0.3 \mathrm{~mol} / \mathrm{L})$, $\mathrm{H}_{2} \mathrm{SO}_{4}(1.88 \mathrm{~mol} / \mathrm{L})$, and $\mathrm{HCl}(1.7 \mathrm{mmol} / \mathrm{L})$ solvents were mixed as chemical compositions of the electrolyte and diluted with distilled water. Then, 2,3-Dimercapto-1-propanesulfonic acid $(2 \mathrm{mg} / \mathrm{L})$ and polyethylene glycol $(1 \mathrm{~g} / \mathrm{L})$ were added as organic additives. In a bathtub, a stainless-steel cathode and $\mathrm{Cu}$ anode were used for electroplating by applying $8 \mathrm{~mA} / \mathrm{cm}^{2} \mathrm{DC}$ at room temperature. Finally, $1.5 \mu \mathrm{m}$ and $5 \mu \mathrm{m}$ thickness of electroplated $\mathrm{Cu}$ films on substrates were obtained by controlling the deposition time. For the magnetron sputtering process, a polycrystalline $\mathrm{Cu}$ material with a two-inch diameter was selected as the sputter target. The vacuum pressure of the deposition chamber was set to $10^{-6}$ Torr initially, and the deposition proceeded at $4 \times 10^{-3}$ Torr. In the vacuum chamber, highpurity argon gas (purity: $99.999 \%$ ) was used as an inert gas during the deposition process. The distance between the target and the substrate was approximately $16 \mathrm{~cm}$. The argon plasma applied by DC power at $150 \mathrm{~W}$ creates a glow discharge between the target and the substrate at room temperature. Finally, a $130 \mathrm{~nm}$ layer $\mathrm{Cu}$ film is generated.

\subsection{Nano Cutting Test}

The strength of the $\mathrm{Cu}$ thin films prepared by electroplating and sputtering was evaluated using nano-cutting, as shown in Figure 2a. To cut the $\mathrm{Cu}$ film, the blade proceeded diagonally, cutting simultaneously in both the horizontal and vertical directions. For the $5 \mu \mathrm{m}$ electroplated $\mathrm{Cu}$ film, the blade was precisely set to a cutting speed of $500 \mathrm{~nm} / \mathrm{s}$ in the horizontal $\left(\mathrm{V}_{\mathrm{h}}\right)$ and $50 \mathrm{~nm} / \mathrm{s}$ in the vertical $\left(\mathrm{V}_{\mathrm{v}}\right)$ direction. For the $1.5 \mu \mathrm{m}$ and $130 \mathrm{~nm} \mathrm{Cu}$ films, the blade was set to a cutting speed of $50 \mathrm{~nm} / \mathrm{s}$ in the horizontal $\left(\mathrm{V}_{\mathrm{h}}\right)$ and $5 \mathrm{~nm} / \mathrm{s}$ in the vertical $\left(\mathrm{V}_{\mathrm{v}}\right)$ direction. The diamond cutting blade has a $2 \mathrm{D}$ geometry, with a $20^{\circ}$ rake angle $(\alpha), 10^{\circ}$ clearance angle (c), and a width of $0.3 \mathrm{~mm}$, as shown in Figure $2 b$. Additionally, the edge radius of the blade measured with a scanning electron microscope (SEM) is approximately $120 \mathrm{~nm}$, which is sharp enough to cut thin films at the submicron scale of thickness [22]. During diagonal cutting, both the cutting force $\mathrm{F}_{\mathrm{c}}$ and thrust force $F_{t}$ were monitored with individual sensors to determine the shear strengths $\left(\tau_{s}\right)$. Figure $3 \mathrm{a}, \mathrm{b}$ show the cutting data for both the $5 \mu \mathrm{m}$ and $1.5 \mu \mathrm{m}$ thick electroplated $\mathrm{Cu}$ films and the $130 \mathrm{~nm}$ thick sputtered $\mathrm{Cu}$ film. Three specimens were tested for both the electroplated and sputtered $\mathrm{Cu}$ films. According to Figure $3 \mathrm{a}$, although both films 
have different thicknesses and were cut at different speeds, the graphs show coincidence in cutting behavior, proving the homogeneous mechanical strength attributed to the same electroplating process. Moreover, the depth of the cut graphs shows that 1.5 and $5 \mu \mathrm{m}$ thicknesses and both $F_{t}$ and $F_{c}$ become zero when the blade cuts the $\mathrm{Cu}$ film through the thickness to the surface of the wafer substrate. For the $5 \mu \mathrm{m} \mathrm{Cu}$ film, $F_{c}$ and $F_{t}$ increased to $1.25 \mathrm{~N}$ and $0.25 \mathrm{~N}$, respectively. For the $1.5 \mu \mathrm{m} \mathrm{Cu}$ film, $F_{c}$ and $F_{t}$ increased to $0.34 \mathrm{~N}$ and $0.2 \mathrm{~N}$, respectively. In addition, both graphs show that $F_{c}$ linearly increases while $F_{t}$ tends to saturate at $5.5 \mu \mathrm{m}$ of a cutting distance, implying that the material cutting behavior changes from elastic to plastic deformation between the blade tip and the $\mathrm{Cu}$ film. Therefore, the second slope of the $\mathrm{F}_{\mathrm{t}}$ data was considered to determine the shear angle and shear strength using Equations (1) and (2), respectively. Considering a very thin film of $130 \mathrm{~nm}$ thickness, however, $120 \mathrm{~nm}$ of the blade edge radius might be blunt and may cause slipping or plowing before the cutting starts. Figure $3 \mathrm{~b}$ shows the cutting result for the $130 \mathrm{~nm}$ sputtered $\mathrm{Cu}$ film. In addition, the depth of the cutting indicates its thickness, and the $F_{c}$ and $F_{t}$ values become zero when the blade reaches the surface of the wafer substrate. In this case, both $F_{t}$ and $F_{c}$ increase without saturation of the $F_{t}$ data. This is because the cutting thickness is relatively thin compared to the sharpness of the tool edge and the friction between the blade and the workpiece [20]. The blunt-blade effect may result in a lower shear angle, yet the shear strength is still considerable because the sputtered $\mathrm{Cu}$ film is cut.

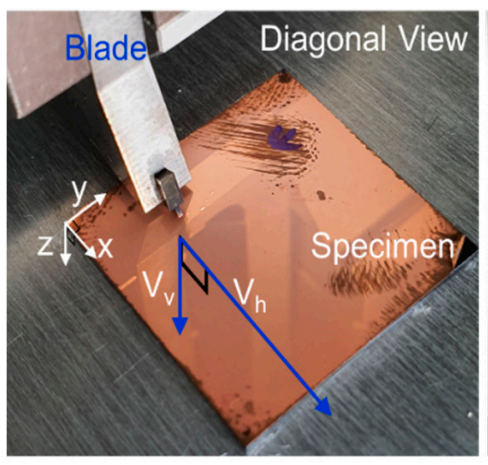

(a)

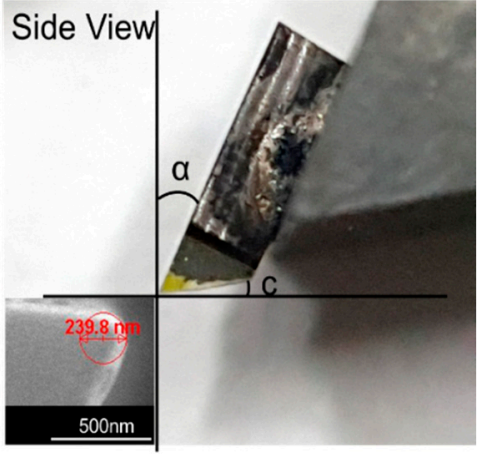

(b)

Figure 2. Nano cutting test and blade: (a) cutting system with specimen; (b) diamond blade and SEM image of the blade edge (lower left).

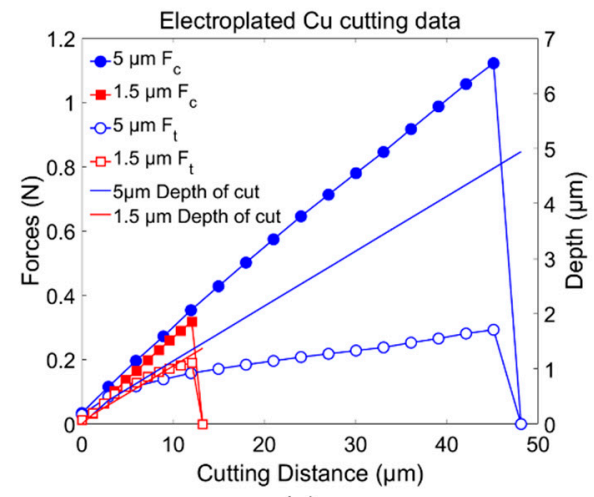

(a)

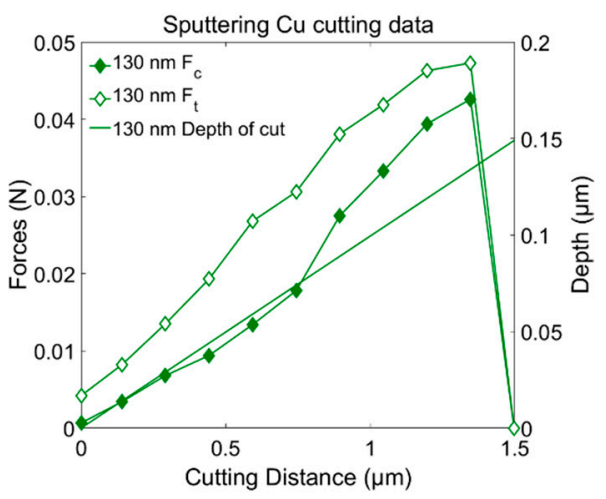

(b)

Figure 3. Cutting data for $\mathrm{Cu}$ thin films: (a) $1.5 \mu \mathrm{m}$ and $5 \mu \mathrm{m}$ electroplating cutting; (b) $130 \mathrm{~nm}$ sputtering cutting.

\subsection{SEM (Scanning Electron Microscopy) and X-ray Diffraction (XRD) Test}

The cracks or pores may be considerable defects of the $\mathrm{Cu}$ films and affect the shear strengths if a significant residual stress occurred after the fabrication process. As surface 
characterization, therefore, SEM (S-4800, Hitachi, Gwangju, Korea, $15.0 \mathrm{kV}$ ) was used to visualize the morphologies and cutting behavior of $\mathrm{Cu}$ films.

XRD analysis is a successful technique to determine the crystallites [23-26]. In particular, Munmun Basak et al. used XRD to quantify the size of crystallites using several models, including the Debye Scherrer method, and verified that the determined crystallite size is very similar to the TEM (Transmission electron microscopy) result [23]. Therefore, the crystallinity of the $\mathrm{Cu}$ films was analyzed using XRD (PANalytical, X'pert Pro MRD, Gwangju, Korea, $\mathrm{Cu}-\mathrm{K} \alpha$ radiation source $(\lambda=0.15406 \mathrm{~nm})$ ). XRD patterns were recorded from $30^{\circ}$ to $80^{\circ}$ with a scanning step of $1.0 \mathrm{~s}$ at $30 \mathrm{~mA}$ and $40 \mathrm{kV}$. The XRD results provide the crystal structure of the $\mathrm{Cu}$ films and the coherent domain size, which is considered as the grain size of the material obtained using the Debye Scherrer equation as Equation (4).

$$
D=\frac{K \lambda}{b \cos \theta},
$$

where $D$ is the coherent domain size, $k$ is the shape factor, $\lambda$ is the $\mathrm{X}$-ray wavelength, $b$ is the full width at half maximum, and $\theta$ is the Bragg angle.

\section{Results and Discussion}

\subsection{Shear Strengths of $\mathrm{Cu}$ Films}

The shear strain on the shear surface during the cutting process is associated with a decrease in the shear angle owing to the thickness reduction, as shown in Figure 1. The decrease in the shear angle occurs when the deformation on the shear surface becomes the largest, which is identified by the shear strain determined using Equation (3). Table 1 lists the mechanical properties of both electroplated and sputtered $\mathrm{Cu}$ films, including the shear angle (Equation (2)), strain (Equation (3)), and strength (Equation (1)). As aforementioned, both 1.5 and $5 \mu \mathrm{m}$ thick electroplated $\mathrm{Cu}$ films show similar values. Conversely, the $130 \mathrm{~nm}$ thick sputtered $\mathrm{Cu}$ film shows a smaller shear angle and larger shear strain and strength compared to the electroplated $\mathrm{Cu}$ films. This result is attributed to both the effect of a relatively blunt blade and the difference in microstructure and grain size of the workpieces obtained by electroplating and sputtering processes.

Table 1. Cutting results for $\mathrm{Cu}$ thin films.

\begin{tabular}{ccccc}
\hline Sample & Test No. & $\varnothing\left(^{\circ}\right)$ & $\gamma$ & $\boldsymbol{\tau}$ (MPa) \\
\hline \multirow{3}{*}{$5 \mu \mathrm{m}$} & 1 & 39.3 & 1.57 & 302.5 \\
Electroplated $\mathrm{Cu}$ & 2 & 40 & 1.56 & 308.4 \\
& 3 & 40.1 & 1.55 & 310.3 \\
& Mean Value & $39.8 \pm 0.4$ & $1.56 \pm 0.01$ & $307.1 \pm 3.3$ \\
\hline \multirow{3}{*}{$1.5 \mu \mathrm{m}$} & 1 & 38.3 & 1.60 & 310.3 \\
Electroplated Cu & 2 & 38.5 & 1.59 & 312.5 \\
& 3 & 40.2 & 1.55 & 316.1 \\
& Mean Value & $39 \pm 0.9$ & $1.58 \pm 0.02$ & $313.0 \pm 2.4$ \\
\hline \multirow{2}{*}{$130 \mathrm{~nm}$} & 1 & 28.3 & 2.00 & 359.4 \\
Sputtered Cu & 2 & 27.3 & 2.07 & 416.8 \\
& 3 & 27.8 & 2.03 & 390.3 \\
\hline
\end{tabular}

Figure 4 shows SEM images of the $\mathrm{Cu}$ film specimens after the cutting test. It should be noted that the blade moved from the left to the right in the images. Figure 4a-c identify the cut area, the exposed surface of the substrate, and the rolled chip for the $130 \mathrm{~nm}$ sputtered $\mathrm{Cu}$ film, and the 1.5 and $5 \mu \mathrm{m}$ electroplated $\mathrm{Cu}$ films, respectively. Figure $4 \mathrm{~d}-\mathrm{f}$ show how the chip is formed and the cutting process. Each length of the cut area corresponds to the cutting distance in Figure 3. The cracks and pores are not observed on the surfaces of the cut area and rolled chips for the three films, which means the residual stresses were low for both film processes. 


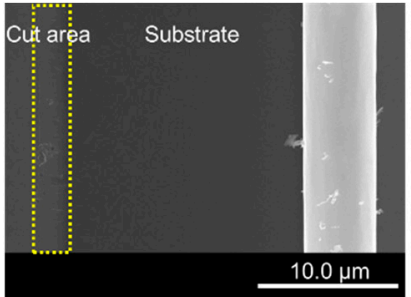

(a)

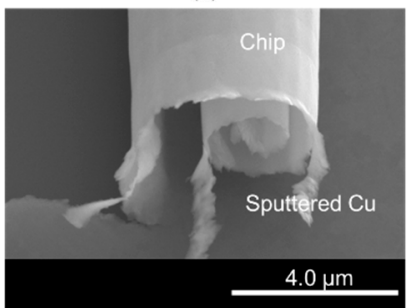

(d)

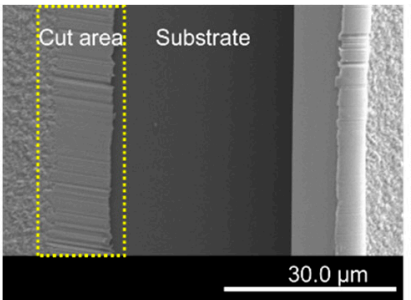

(b)

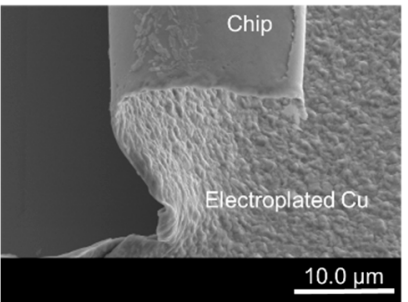

(e)

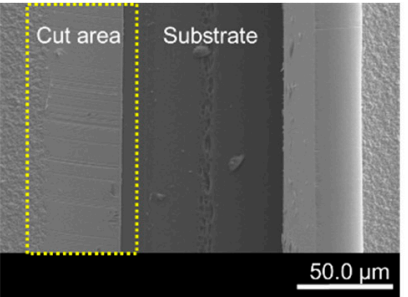

(c)

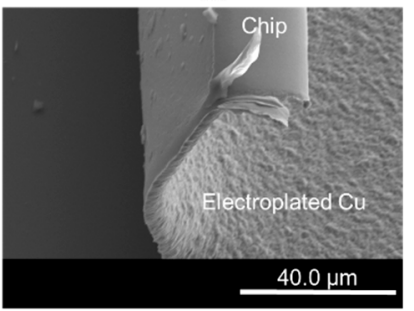

(f)

Figure 4. Morphology of cut $\mathrm{Cu}$ films: (a) top view of the sputtering $\mathrm{Cu}(130 \mathrm{~nm})$; (b) top view of the electroplated $\mathrm{Cu}(1.5 \mu \mathrm{m})$; (c) top view of the electroplated $\mathrm{Cu}(5 \mu \mathrm{m})$; (d) cutting chip of the sputtered $\mathrm{Cu}$ film $(130 \mathrm{~nm})$; (e) cutting chip of the electroplated $\mathrm{Cu}$ film $(1.5 \mu \mathrm{m})$; (f) cutting chip of the electroplated $\mathrm{Cu}$ film $(5 \mu \mathrm{m})$.

\subsection{X-ray Diffraction (XRD) Analysis}

As shown in Figure 5, the peaks are formed at Bragg angles of $43.4^{\circ}, 50.5^{\circ}, 69.2^{\circ}$ and $74.2^{\circ}$. It was found that diffraction peaks with strong intensities appear at angles corresponding to (111), (200), and (220) planes of electroplated $\mathrm{Cu}$ and (111) and (200) planes for sputtered $\mathrm{Cu}$ film. For three films, (400) planes indicate the Si wafer as the substrate. The electroplated $\mathrm{Cu}$ films show the same results as conventional $\mathrm{Cu}$ films. However, the sputtering $\mathrm{Cu}$ thin film has no peak at $74.2^{\circ}$, and the intensity of $50.5^{\circ}$ is also weaker than that of electroplated workpieces.

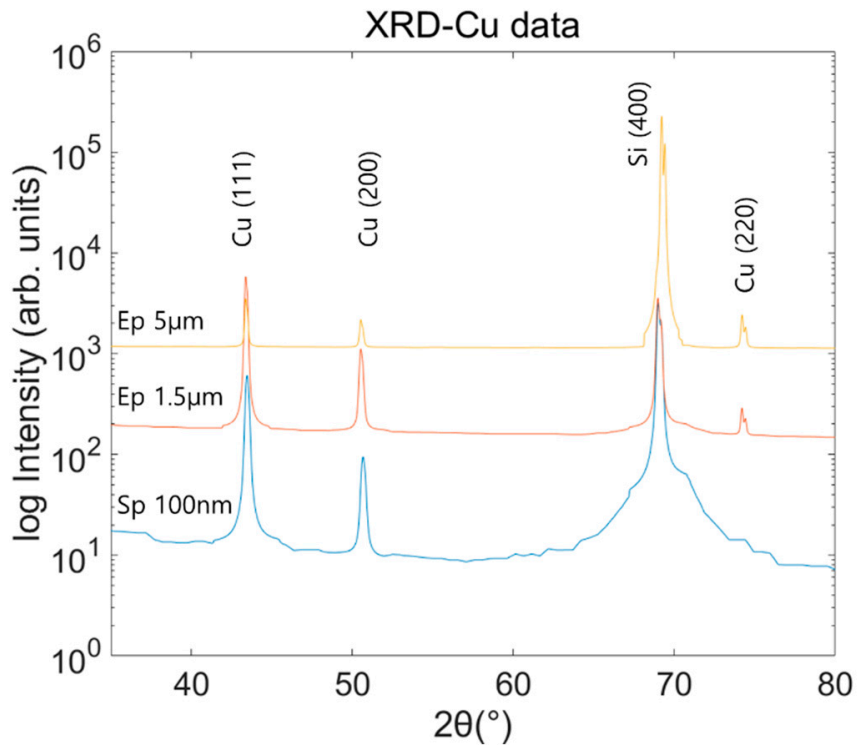

Figure 5. XRD analysis of the tested $\mathrm{Cu}$ films.

The coherent domain sizes of the $\mathrm{Cu}$ thin films were determined through XRD analysis, and the results are listed in Table 2. For both electroplated $\mathrm{Cu}$ films, the average domain sizes were similarly determined as $67.0 \pm 5.5 \mathrm{~nm}(5 \mu \mathrm{m})$ and $59.1 \pm 8.3 \mathrm{~nm}(1.5 \mu \mathrm{m})$, respectively. However, for the sputtered $\mathrm{Cu}$ film, the average domain size was determined as $39.3 \pm 2.1 \mathrm{~nm}$, which is smaller than that of the electroplated $\mathrm{Cu}$ film. According to the 
Hall-Petch theory, materials with smaller grain sizes have larger strengths [27,28]. This was confirmed by comparing the shear strength of the proposed nano-cutting tests for electroplated and sputtered $\mathrm{Cu}$ films. It was found that the shear strength of the sputtered $\mathrm{Cu}$ film was approximately $20 \%$ higher.

Table 2. Coherent domain size of $\mathrm{Cu}$ thin films.

\begin{tabular}{|c|c|c|}
\hline Sample & (hkl) & Coherent Domain Size (nm) \\
\hline \multirow{4}{*}{ Electroplated Cu $5 \mu \mathrm{m}$} & $(111)$ & 72.4 \\
\hline & $(200)$ & 59.5 \\
\hline & $(220)$ & 69.2 \\
\hline & Average & $67.0 \pm 5.5$ \\
\hline \multirow{4}{*}{ Electroplated $\mathrm{Cu} 1.5 \mu \mathrm{m}$} & (111) & 59.4 \\
\hline & $(200)$ & 48.8 \\
\hline & $(220)$ & 69.2 \\
\hline & Average & $59.1 \pm 8.3$ \\
\hline \multirow{3}{*}{ Sputtered Cu $130 \mathrm{~nm}$} & $(111)$ & 41.4 \\
\hline & $(200)$ & 37.2 \\
\hline & Average & $39.3 \pm 2.1$ \\
\hline
\end{tabular}

\section{Conclusions}

We report a method to determine the shear strength and strain as mechanical properties of thin films using the nano-cutting technique. In this study, electroplated $\mathrm{Cu}$ films with thicknesses of $5 \mu \mathrm{m}$ and $1.5 \mu \mathrm{m}$ and sputtered $\mathrm{Cu}$ films with a thickness of $130 \mathrm{~nm}$ were evaluated. For the electroplated copper thin films of 1.5 and $5 \mu \mathrm{m}$, the shear strength was approximately $307 \mathrm{MPa}$ and $313 \mathrm{MPa}$, and the shear strain was 1.56 and 1.58, respectively. These close results are a result of the same electroplating process. However, for the $130 \mathrm{~nm}$ sputtered $\mathrm{Cu}$ thin films, the shear strength was found to be $388.8 \mathrm{MPa}$, and the shear strain was 2.03 . This is $20 \%$ higher than that of the electroplated $\mathrm{Cu}$ thin films. In addition, XRD analysis was conducted to determine the difference in the nanocrystalline structure of the films, and the coherent domain size was obtained using the Debye-Scherrer equation, which is considered as the grain size. The electroplated $\mathrm{Cu}$ thin films have a coherent domain size of approximately $60 \sim 67 \mathrm{~nm}$, while the sputtering $\mathrm{Cu}$ thin films show $39 \mathrm{~nm}$. Therefore, larger shear strength and strain for the sputtered $\mathrm{Cu}$ film were expected.

Author Contributions: Conceptualization, J.B.K. and J.-H.L.; data curation, J.-H.L.; formal analysis, J.B.K. and J.-H.L.; validation, J.-H.L. and J.B.K.; investigation, J.B.K. and J.-H.L.; writing-original draft preparation, J.-H.L.; writing-review and editing, J.B.K. All authors have read and agreed to the published version of the manuscript.

Funding: This study was supported by the National Research Foundation of Korea (NRF) grant funded by the Korea government (Ministry of Science and ICT) (NRF-2021R1A2C1007016).

Institutional Review Board Statement: Not applicable.

Informed Consent Statement: Not applicable.

Data Availability Statement: Data sharing is not applicable to this article.

Conflicts of Interest: The authors declare no conflict of interest.

\section{References}

1. Kang, C.-W.; Huang, H. Deformation, failure and removal mechanisms of thin film structures in abrasive machining. Adv. Manuf. 2017, 5, 1-19. [CrossRef]

2. Jörg, T.; Music, D.; Hauser, F.; Cordill, M.J.; Franz, R.; Köstenbauer, H.; Winkler, J.; Schneider, J.; Mitterer, C. Deformation behavior of Re alloyed Mo thin films on flexible substrates: In situ fragmentation analysis supported by first-principles calculations. Sci. Rep. 2017, 7, 7374. [CrossRef] [PubMed]

3. Spearing, S. Materials issues in microelectromechanical systems (MEMS). Acta Mater. 2000, 48, 179-196. [CrossRef]

4. Nix, W.D. Mechanical properties of thin films. Metall. Trans. A 1989, 20, 2217-2245. [CrossRef] 
5. Poon, B.; Rittel, D.; Ravichandran, G. An analysis of nanoindentation in linearly elastic solids. Int. J. Solids Struct. 2008, 45, 6018-6033. [CrossRef]

6. Antunes, J.; Fernandes, J.; Sakharova, N.; Oliveira, M.; Menezes, L. On the determination of the Young's modulus of thin films using indentation tests. Int. J. Solids Struct. 2007, 44, 8313-8334. [CrossRef]

7. Mehrotra, K.; Oliver, J.B.; Lambropoulos, J.C. Nano-indentation of single-layer optical oxide thin films grown by electron-beam deposition. Appl. Opt. 2015, 54, 2435-2440. [CrossRef]

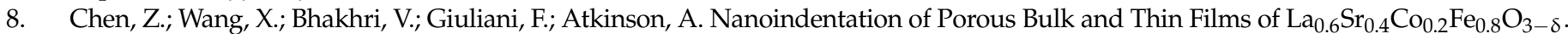
Acta Mater. 2013, 61, 5720-5734. [CrossRef]

9. Xia, W.; Song, J.; Hsu, D.D.; Keten, S. Understanding the Interfacial Mechanical Response of Nanoscale Polymer Thin Films via Nanoindentation. Macromolecules 2016, 49, 3810-3817. [CrossRef]

10. Du, Y.; Xu, T.; Shaw, T.M.; Liu, X.H.; Bonilla, G.; Li, H.; Lu, H. A novel tri-layer nanoindentation method to measure the mechanical properties of a porous brittle ultra-low-k dielectric thin film. Extreme Mech. Lett. 2017, 13, 100-107. [CrossRef]

11. Zhou, Y.; Yang, C.S.; Chen, J.A.; Ding, G.F.; Ding, W.; Wang, L.; Wang, M.; Zhang, Y.; Zhan, T. Measurement of Young's modulus and residual stress of copper film electroplated on silicon wafer. Thin Solid Film. 2004, 460, 175-180. [CrossRef]

12. Richter, F.; Herrmann, M.; Molnar, F.; Chudoba, T.; Schwarzer, N.; Keunecke, M.; Bewilogua, K.; Zhang, X.W.; Boyen, H.G.; Ziemann, P. Substrate influence in Young's modulus determination of thin films by indentation methods: Cubic boron nitride as an example. Surf. Coat. Technol. 2006, 201, 3577-3587. [CrossRef]

13. Chen, S.; Liu, L.; Wang, T. Investigation of the mechanical properties of thin films by nanoindentation, considering the effects of thickness and different coating-substrate combinations. Surf. Coat. Technol. 2005, 191, 25-32. [CrossRef]

14. Saha, R.; Nix, W.D. Effects of the substrate on the determination of thin film mechanical properties by nanoindentation. Acta Mater. 2002, 50, 23-38. [CrossRef]

15. Pham, V.-T.; Fang, T.-H. Pile-up and heat effect on the mechanical response of SiGe on Si(l 001$)$ substrate during nanoscratching and nanoindentation using molecular dynamics. Comput. Mater. Sci. 2019, 174, 109465. [CrossRef]

16. Xiang, Y.; Chen, X.; Vlassak, J.J. The Mechanical Properties of Electroplated Cu Thin Films Measured by means of the Bulge Test Technique. MRS Proc. 2001, 695, 491. [CrossRef]

17. Xiang, Y.; Tsui, T.; Vlassak, J. The mechanical properties of freestanding electroplated Cu thin films. J. Mater. Res. 2006, 21, 1607-1618. [CrossRef]

18. Merchant, M.E. Mechanics of the Metal Cutting Process. I. Orthogonal Cutting and a Type 2 Chip. J. Appl. Phys. 1945, 16, 267-275 [CrossRef]

19. Saito, F.; Nishiyama, I.; Hyodo, T. Cutting strength-A new indicator for the mechanical strength of materials. Mater. Lett. 2012, 66, 144-146. [CrossRef]

20. Yin, K.; Xia, Y.; Chan, C.; Zhang, W.; Wang, Q.; Zhao, X.; Li, A.; Liu, Z.; Bayes, M.; Yee, K. The kinetics and mechanism of room-temperature microstructural evolution in electroplated copper foils. Scr. Mater. 2008, 58, 65-68. [CrossRef]

21. Kim, H.S. Formation of Crystalline Copper Thin Films by a Sputtering-assisted Magnetic Field System at Room Temperature. Appl. Sci. Converg. Technol. 2018, 27, 1-4. [CrossRef]

22. Son, S.M.; Lim, H.S.; Ahn, J.H. Effects of the friction coefficient on the minimum cutting thickness in micro cutting. Int. J. Mach. Tools Manuf. 2005, 45, 529-535. [CrossRef]

23. Basak, M.; Rahman, L.; Ahmed, F.; Biswas, B.; Sharmin, N. The use of X-ray diffraction peak profile analysis to determine the structural parameters of cobalt ferrite nanoparticles using Debye-Scherrer, Williamson-Hall, Halder-Wagner and Size-strain plot: Different precipitating agent approach. J. Alloy. Compd. 2021, 895, 162694. [CrossRef]

24. Nath, S.S.; Chakdar, D.; Gope, G. Synthesis of CdS and ZnS quantum dots and their applications in electronics, Nanotrends. J. Nanotechnol. Its Appl. 2007, 2, 1-3.

25. Nath, S.S.; Chakdar, D.; Gope, G.; Avasthi, D.K. Effect of $100 \mathrm{Mev}$ Nickel Ions on Silica Coated ZnS Quantum Dot. J. Nanoelectron. Optoelectron. 2008, 3, 1-4. [CrossRef]

26. Mustapha, S.; Ndamitso, M.M.; Abdulkareem, A.S.; Tijani, J.O.; Shuaib, D.T.; Mohammed, A.K.; Sumaila, A. Comparative study of crystallite size using Williamson-Hall and Debye-Scherrer plots for ZnO nanoparticles. Adv. Nat. Sci. Nanosci. Nanotechnol. 2019, 10, 045013. [CrossRef]

27. Song, D.; Li, C.; Liang, N.; Yang, F.; Jiang, J.; Sun, J.; Wu, G.; Ma, A.; Ma, X. Simultaneously improving corrosion resistance and mechanical properties of a magnesium alloy via equal-channel angular pressing and post water annealing. Mater. Des. 2019, 166, 107621. [CrossRef]

28. Neh, K.; Ullmann, M.; Kawalla, R. Effect of Grain refining Additives on Microstructure and Mechanical Properties of the Commercial Available Magnesium alloys AZ31 and AM50. Mater. Today: Proc. 2015, 2, S219-S224. [CrossRef] 